\title{
Kinetics of nitrogen removal processes in constructed wetlands
}

\author{
Magdalena Gajewska ${ }^{1, *}$, Katarzyna Skrzypiec $^{1}$ \\ ${ }^{1}$ Gdańsk University of Technology, Faculty of Civil and Environmental Engineering, Narutowicza St. 11/12, 80-233, Gdańsk, \\ Poland
}

\begin{abstract}
The aim of this paper is to present a state-of-the-art review of the kinetics of nitrogen removal in constructed wetlands. Biological processes of nitrogen removal from wastewater can be described using equations and kinetic models. Hence, these kinetic models which have been developed and evaluated allow for predicting the removal of nitrogen in treatment wetlands. One of the most important, first order removal model, which is still applied, was analysed and its rate coefficients and factors were compared. This study also demonstrates the validity of Monod and multiple Monod kinetics, commonly seen today. Finally, a computational example of the reaction kinetics of nitrogen removal was also included in the study.
\end{abstract}

\section{Introduction}

Several studies have shown the overall effectiveness of constructed wetlands (CWs) in treating municipal wastewater and in removing nitrogen rather effectively. Nitrogen removal is achieved not only by bacteria, but also by plant uptake, adsorption, where ionized ammonia reacts with the media in subsurface horizontal flow (SSHF) constructed wetlands, and volatilization in surface flow (SF) wetlands, where under high $\mathrm{pH}$ values the aquatic ammonium phase transforms to gaseous ammonia $[5,6,9,10]$.

Despite the complexity of all biological processes of nitrogen removal in treatment wetland systems, they can be described by relatively uncomplicated equations. Different mathematical models were used to study the process kinetics of the nitrogen removal, mainly first and second order reaction models. Kinetic models developed from different combinations of first-order, Monod kinetics as well as continuous stirred-tank reactor and plug flow patterns can be applied in the design of constructed wetlands for wastewater treatment.

\section{Nitrogen removal in constructed wetlands}

\subsection{Processes and mechanisms}

A number of processes transfer nitrogen compounds from one point to another in wetlands without resulting in a molecular transformation. These physical transfer processes include, but are not limited to the following: particulate settling and resuspension, diffusion of dissolved forms, plant translocation, litterfall, ammonia volatilization, and sorption of soluble nitrogen on substrates. In addition to the physical translocation of nitrogen compounds in wetlands, five principal processes transform nitrogen from one form to another: ammonification (mineralization), nitrification, denitrification, assimilation, and decomposition. Due to the low oxygen and organic matter concentration in the root-zone of subsurface flow constructed wetlands, which are limiting factors for nitrification and denitrification processes, a combination of partial nitrification and anaerobic ammonium oxidation has also been suggested as possible pathway for nitrogen removal in constructed wetlands. Because the Anammox process is autotrophic, the complete conversion of ammonium to nitrogen gas can take place without the addition of organic matter. A detailed understanding of these nitrogen transfer and transformation processes is important for understanding wetland treatment systems $[1,10,12,17]$.

\subsection{Role of plants in nitrogen removal}

There are many effects of vegetation on nitrogen processing and removal in treatment wetlands. Firstly, the plant growth cycle seasonally stores and releases nitrogen, thus providing a "fly-wheel" effect for nitrogen removal time series. Moreover, stable residuals which are created and accreted in the wetlands contain nitrogen as part of their structure, and hence accretion represents a burial process for nitrogen. Another example is submersed litter and stems that provide surfaces on which microbes residue. These include nitrifiers and denitrifiers. The presence of vegetation also influences the supply of oxygen to the water. Emergent vegetation blocks the wind, and shades out algae, presumably lowering reaeration. Floating vegetation may provide a barrier to atmospheric oxygen transfer. Submersed vegetation may provide photosynthetic oxygen supply directly in the water. To some extent, plant oxygen flux supplies protective nitrification in the immediate vicinity of plant roots. Last but not least, carbon content of plant

\footnotetext{
* Corresponding author: mgaj@gda.edu.pl
} 
litter supplies the energy need for heterotrophic denitrifiers [4, 8].

\section{Kinetic models}

\subsection{First-order kinetics - rate coefficients (k)}

The speed of pollutant removal is typically represented by a rate coefficient, $k$ :

$$
J=k \cdot C
$$

where: $C=$ concentration, $\mathrm{g} \cdot \mathrm{m}^{-3}, J=$ removal per unit area, or load removed, $\mathrm{g} \cdot \mathrm{m}^{-2} \cdot \mathrm{d}^{-1}, k=$ rate coefficient, $\mathrm{m} \cdot \mathrm{d}^{-1}$.

This parameter is dependent on factors such as pollutant loading, oxygen transfer, presence of vegetation, etc. Different wetlands will have different $k$ rates, but central tendencies in $k$ can be observed. Most processes in wetlands are dependent on wetland area, so $k$-rates uses in the wetland literature are often area-based coefficients $\left(k_{A}\right)$. In some intensified wetlands (such as aerated or fill-and-drain wetlands) treatment is dependent on reactor volume, so volume-based rate coefficients $\left(k_{V}\right)$ are sometimes used. K-rates are usually corrected to a temperature standard of $20{ }^{\circ} \mathrm{C}$ in the literature $[2,10]$.

The majority of the models of constructed wetlands are focused on input-output data and the production of either linear regression equations or first order decay laws. The most common form of the first order equations is presented by following equation:

$$
C_{\text {out }} / C_{\text {in }}=\exp \left(-k_{A} / q\right)
$$

where $q$ is the hydraulic loading rate in $\mathrm{m} \cdot \mathrm{d}^{-1}$ and $k_{A}$ the decomposition constant in $\mathrm{m} \cdot \mathrm{d}^{-1}$. Another form of the first order equation, which uses the hydraulic residence time (HRT, $t$ ) in days, is presented in (3):

$$
C_{\text {out }} / C_{\text {in }}=\exp \left(-k_{v} t\right)
$$

The temperature $(T)$ effect in foregoing equations is expressed by the constant $k_{T}\left(k_{A}\right.$ or $\left.k_{v}\right)$, which is determined by the use of an Arrhenious equation, as follows:

$$
k_{T}=k_{20} \theta^{(T-20)}
$$

where $k_{20}\left(k_{A, 20}\right.$ or $\left.k_{v, 20}\right)$ is the value of $k_{T}$ at $20{ }^{\circ} \mathrm{C}$. The $k_{20}$ and $\theta$ constants usually result from a statistical analysis of the data used in model production. Typical values for $k_{A}$ are between 0.06 and $0.16 \mathrm{~m} \cdot \mathrm{d}^{-1}$, for $k_{v}$ between 0.007 and $0.10 \mathrm{~m} \cdot \mathrm{d}^{-1}$ and the suggested value for $\theta$ is 1.05 . If $\theta>1$, reaction rates slow down with colder water temperatures. If $\theta<1$, reaction rates increase with colder water temperatures $[1,2]$.

\subsection{Background concentrations $\left(C^{*}\right)$}

Internal physical, chemical, and biological treatment cycles within wetlands process, store and release different compounds, this results in non-zero background concentrations for certain compounds. This particularly affects organic matter, nitrogen, phosphorus, and pathogens. Background concentrations may vary on an annual or seasonal basis, depending on the internal cycles involved. These non-zero background concentrations are commonly denoted by the term $C^{*}[2$, $10]$.

\section{3 $P-k-C^{*}$ modelling}

Real-world wetlands do not follow the idealized Plug Flow or CSTR (Continuously Stirred Tank Reactor) models. Some short-circuiting and dispersion always occurs in real-world wetlands. This is best represented by a Tank-In Series (TIS) flow model, which is an intermediate case between the Plug Flow and CSTR extremes. In Tank-In-Series (TIS) Flow Model, the number of tanks-in-series $(\mathrm{N})$ is a mathematical representation of the hydraulic performance of a wetland, not the physical number of cells in the system. $\mathrm{N}=\infty$ is equivalent to plug flow and $\mathrm{N}=1$ is equivalent to a CSTR [2].

The concepts of non-ideal flow and pollutant weathering $(P)$, first-order kinetics $(k)$ and non-zero background concentrations $\left(C^{*}\right)$ can be combined into a single equation to predict wetland treatment performance. First order plug flow reaction kinetics are commonly used to describe pollutant removal in wetland systems, particularly for $\mathrm{BOD}_{5}$ and nitrogen removal. The first order plug flow equation incorporating background concentrations is described in (5). It is modified first order $k$ - $C^{*}$ model in which the concentration varies with residence time $t$ through the constants $C_{0}$ the initial concentration, $C^{*}$ a residual concentration, and $k$ the volumetric rate constant. Because the $k-C^{*}$ model contains both exponential and linear terms, it cannot be transformed into a simple linear model for statistical calibration.

$$
\left(C-C^{*}\right) /\left(C_{i}-C^{*}\right)=\exp (-k t)
$$

where $C=$ effluent concentration, $C_{i}=$ influent concentration, $C^{*}=$ background concentration, $k=$ kinetic rate constant. Background concentration is a portion of the $C$ in that is immediately settled down at the unit inlet, and cannot be removed; it is of the order $10-20 \mathrm{mg} \cdot \mathrm{L}^{-1}[1,2,11,14]$.

It has been proven that the first order plug-flow kinetic model with background concentrations effectively describes both TKN and $\mathrm{NH}_{4}-\mathrm{N}$ removal rates from the SSF and SF wetlands and pond cells with correlation coefficients ranging from $\mathrm{R}^{2}=0.52$ to $\mathrm{R}^{2}=$ 0.86 [11].

In order to derive $\mathrm{k}$-values from the available data, the first order P-k-C* model presented by Kadlec and Wallace [10] was used:

$$
\left(C_{0}-C^{*}\right) /\left(C_{i}-C^{*}\right)=1 /(1+k / P q)^{P}
$$

where $C_{0}=$ outlet concentration, $\mathrm{g} \cdot \mathrm{m}^{-3} ; C_{i}=$ inlet concentration, $\mathrm{g} \cdot \mathrm{m}^{-3} ; C^{*}=$ background concentration, $\mathrm{g} \cdot \mathrm{m}^{-3} ; k=$ first-order areal rate coefficient, $\mathrm{m} \cdot$ year $^{-1} ; P=$ 
apparent number of tanks in series; and $q=$ hydraulic loading rate, $\mathrm{m} \cdot \mathrm{year}^{-1}$. The $\mathrm{P}-\mathrm{k}-\mathrm{C} *$ model has been proposed by as being generally the most appropriate kinetic model for predicting outlet concentrations of pollutants displaying first order removal in treatment wetlands. This model incorporates an aspect of the wetland internal hydraulic characteristics in the form of the parameter $P$, which represents the degree of mixing and approximates the number of completely mixed tanks connected in series $[5,10]$.

As mentioned before, the most commonly used equation for TN removal in subsurface flow constructed wetlands is the first order equation. According to this approach, the hydrodynamic operation of the wetlands resembles that of plug-flow reactors (PFR), and there is a first order decay of TN with time. Using the TN removal definition [1]:

$$
R_{T N}=\left(C_{\text {in }}-C_{\text {out }}\right) / C_{\text {in }}
$$

the right hand side of (7) becomes:

$$
1-R=\exp \left(-k_{v} t\right)
$$

\subsection{Design features}

To estimate the surface area of the SSHF system $\left(A_{H F}\right)$ needed to reduce total nitrogen concentration to the target value using empirically determined first-order degradation rate constant $\left(K_{T N}\right)$ and background $\mathrm{TN}$ concentrations, following equation shall be used:

$$
A_{H F}=\left(Q_{a v} / K_{T N}\right) \ln \left(\left(C_{i}-C^{*}\right) /\left(C_{0}-C^{*}\right)\right)
$$

where $A_{H F}=$ required surface area of bed $\left(\mathrm{m}^{2}\right), Q_{a v}=$ average water flow rate $\left(\mathrm{m}^{3} \cdot \mathrm{d}^{-1}\right), C_{0}=$ effluent target $\mathrm{TN}$ concentration $\left(\mathrm{mg} \cdot \mathrm{L}^{-1}\right), C_{i}=$ influent $\mathrm{TN}, C^{*}=$ background TN concentration $\left(\mathrm{mg} \cdot \mathrm{L}^{-1}\right), K_{T N}=$ first-order areal rate constant $\left(\mathrm{m} \cdot \mathrm{d}^{-1}\right)$. The rate constant can be set to: $K_{T N}=12 \mathrm{~m} \cdot$ year $^{-1}$. The background concentration for total $\mathrm{N}$ can be set to $2 \mathrm{mg} \cdot \mathrm{L}^{-1}[3,16]$.

\subsection{Application of artificial neural networks}

Artificial neural networks are able to model TN removal in horizontal subsurface flow constructed wetlands. The performance of the networks was found to be reasonably good for wetland design purposes. A design equation for $\mathrm{TN}$ removal is proposed as an alternative to the first order model. This equation is based on the ANN (artificial neural networks) response curves, and it reads:

$$
R_{T N}=H R T /(K+H R T)
$$

with

$$
K=(22.8 / T) 45.5(n /(1-n))^{3}
$$

where $H R T$ and $K$ are in days, $n$ is the porosity and $(n /(1-n))^{3}$ is an expression entering many formulas predicting hydraulic conductivities in porous media. The hyperbolic equation above combines zero and first order kinetics, as this is considered most handy for design of wetlands [1].

\subsection{Models based on Monod and multiple Monod kinetics}

So far, a few models have been established by combining first-order, Monod and multiple Monod kinetics with continuous stirred-tank reactor (CSTR) flow pattern. Monod kinetics, which contains the parameters of substrate concentration $\left(C_{\text {out }}\right)$, half saturation constant of limiting substrate $\left(C_{\text {half }}\right)$ and maximum pollutant removal rates $\left(K_{\max }\right)$, can be expressed as:

$$
\mathrm{d} C / \mathrm{d} t=-K_{\max }\left(C_{\text {out }}\left(\left(C_{\text {half }}+C_{\text {out }}\right)\right)\right.
$$

Combining CSTR flow pattern with Monod kinetics gives (13), which links inlet and outlet pollutant concentrations:

$$
\left(C_{\text {in }}-C_{\text {out }}\right) / \tau=-K_{\max }\left(C_{\text {out }} /\left(C_{\text {half }}+C_{\text {out }}\right)\right)
$$

Equation above is expressed in terms of hydraulic retention time $\tau$ (units in days). The relation between hydraulic retention time, area $\left(A, \mathrm{~m}^{2}\right)$, depth $(h, \mathrm{~m})$, porosity $(\varepsilon)$ of packed media and inlet discharge $(Q$, $\mathrm{m}^{3} \cdot \mathrm{d}^{-1}$ ) can be expressed in (14).

$$
\tau=A h \varepsilon / Q
$$

Combining volumetric maximum pollutant removal rates $\left(K_{\max }, \mathrm{g} \cdot \mathrm{m}^{-3} \cdot \mathrm{d}^{-1}\right)$ with $h$ and $(\varepsilon)$ results areal maximum pollutant removal rates $\left(K_{2}, \mathrm{~g} \cdot \mathrm{m}^{-2} \cdot \mathrm{d}^{-1}\right)$ to correlate inlet and outlet pollutant concentrations.

$$
K_{2}=q\left(C_{\text {in }}-C_{\text {out }}\right)\left(C_{\text {half }}+C_{\text {out }}\right) / C_{\text {out }}
$$

Multiple Monod kinetics assumes that more than one substrate can limit the rate of pollutant degradation. The multiple Monod kinetics can be expressed in the following equation:

$$
\frac{d C}{d t}=-K_{\max }\left(\frac{C_{o u t 1}}{C_{\text {half } 1}+C_{\text {out } 1}}\right)\left(\frac{C_{\text {out } 2}}{C_{\text {half } 2}+C_{\text {out } 2}}\right)
$$

$C_{\text {out } 1}$ and $C_{\text {out } 2}$ represent the outlet concentrations of two substrates that may limit the biodegradation rate of target pollutant, while $C_{\text {half } 1}$ and $C_{\text {half } 2}$ are the half saturate constants for these substrates. Eq. (17) links inlet and outlet pollutant concentration and $\mathrm{K}_{3}$ value (maximum areal pollutant removal rate $\mathrm{K}_{3}, \mathrm{~g} \cdot \mathrm{m}^{-2} \cdot \mathrm{d}^{-1}$ ).

$$
K_{3}=\frac{q\left(C_{\text {in }}-C_{\text {out }}\right)\left(C_{\text {out } 1}+C_{\text {half } 1}\right)\left(C_{\text {out } 2}+C_{\text {half } 2}\right)}{C_{\text {out } 1} C_{\text {out } 2}}
$$

The kinetic coefficients (derived from Monod/ multiple Monod kinetics) tend to increase with pollutant loading, indicating that the coefficients may vary based on different factors, such as influent pollutant concentration, hydraulic loading, and water depth [13, $15,16]$. 


\section{Calculation example}

The reaction kinetics calculations were performed for the SF (Surface Flow) wetland system.

- Influent flow rate $(Q)=180 \mathrm{~m}^{3} \cdot \mathrm{d}^{-1}=65700 \mathrm{~m}^{3} \cdot \mathrm{y}^{-1}$,

- Influent BOD $\left(C_{i}\right)=300 \mathrm{mg} \cdot \mathrm{L}^{-1}$,

- $\mathrm{SF}$ area $(A)=1$ ha $=10000 \mathrm{~m}^{2}$.

What is the effluent concentration $(C)$ at $20^{\circ} \mathrm{C}$ ? Assume $k_{A}=36 \mathrm{~m} \cdot \mathrm{y}^{-1}$ and $P=3$.

$$
\begin{gathered}
\frac{C-C^{*}}{C_{i}-C^{*}}=\frac{1}{(1+k / P q)^{P}} \\
q=\frac{Q}{A}=\frac{65700 \mathrm{~m}^{3} \cdot y^{-1}}{10000 \mathrm{~m}^{2}}=6.57 \mathrm{~m} \cdot \mathrm{y}^{-1}
\end{gathered}
$$

Background concentrations in SF wetlands for BOD can be expressed as an empirical relationship based on curve fitting to existing data sets:

$$
C^{*}=0.6+0.065 C_{i}=0.6+0.065 \cdot 300=20.10 \mathrm{mg} \cdot \mathrm{L}^{-1}
$$

Effluent concentration at $20^{\circ} \mathrm{C}$ is:

$$
C=\frac{C_{i}-C^{*}}{(1+k / P q)^{P}}+C^{*}=\frac{300-20.10}{(1+36 / 3 \cdot 6.57)^{3}}+20.10=32.50 \mathrm{mg} \cdot L^{-1}
$$

What is the effluent concentration $(C)$ at $10{ }^{\circ} \mathrm{C}$ ? Assume $k_{A}=37 \mathrm{~m} \cdot \mathrm{y}^{-1}$ at $20^{\circ} \mathrm{C}$ and $\theta=0.985$.

$$
k_{T=10^{\circ} \mathrm{C}}=k_{20} \theta^{(T-20)}=37 \cdot 0.985^{(10-20)}=43 m \cdot y^{-1}
$$

Effluent concentration at $10^{\circ} \mathrm{C}$ is:

$C=\frac{C_{i}-C^{*}}{(1+k / P q)^{P}}+C^{*}=\frac{300-20.10}{(1+43 / 3 \cdot 6.57)^{3}}+20.10=27.78 \mathrm{mg} \cdot L^{-1}$

With a slight change in the $k$ coefficient at lower temperature $\left(10^{\circ} \mathrm{C}\right)$, a greater reduction in BOD concentration occurs than at $20{ }^{\circ} \mathrm{C}$. This confirms that when $\theta<1$ and at lower temperatures, the reaction rates increase.

\section{Summary}

First-order, area-based nitrogen loss models provide a suitable method for design of wetland treatment systems in most circumstances. These have the advantage of correctly describing internal phenomena in flow through wetlands, as well as describing batch wetland operation. Studies on side-by-side wetlands confirm the effects of the principal variables of inlet concentrations and hydraulic loading rates (or the equivalent detention times). The parent mass balance equation for water movement may be adjusted to fit extreme environmental conditions of precipitation or evapotranspiration. The rate equations account for return fluxes from the wetland biomass, and thus can fit the entire range of hydraulic loadings. In parameter estimation, the sequential nature of the nitrogen transformations cannot be ignored.

\section{References}

1. C.S. Akratos, J.N.E. Papaspyros, V.A. Tsihrintzis, Bioresour. Technol. 100, 586 (2009)

2. C.A. Arias, T.R. Headley, P. Carvalho, Constructed Wetlands For Water Pollution Control - PhD training course materials, 18-24 (Aarhus University, Denmark, 2017)

3. H. Brix, N.H. Johansen, Nutrient Cycling and Retention in Natural and Constructed Wetlands, 155 (Publishers, Leiden, The Netherlands, 1999)

4. J. Fan, W. Wang, B. Zhang, Y. Guo, H.H. Ngo, W. Guo, J. Zhang, H. Wu, Bioresour. Technol. 143, 461 (2013)

5. M. Gajewska, H. Obarska-Pempkowiak, Environ. Prot. Eng. 37, 27 (2011)

6. M. Gajewska, K. Ambroch, Pol. J. Environ. Stud. 21, 65 (2012)

7. T.R. Headley, C.C. Tanner, Crit. Rev. Environ. Sci. Technol. 42, 2261 (2012)

8. R.H. Kadlec, Natural and Constructed wetlands: Nutrients, Metals and Management, 233 (Backhuys Publishers, Leiden, The Netherlands 2005)

9. R. Kadlec, R. Knight, Treatment Wetlands (CRC Press, 1996)

10. R.H. Kadlec, S. Wallace, Treatment Wetlands, Second Edition (CRC Press, Boca Raton 2009)

11. C.B. Kinsley, A.M. Crolla, N. Kuyucak, M. Zimmer, A. Lafleche, Water Sci Technol. 56, 151 (2007)

12. D. Paredes, P. Kuschk, F. Stange, R.A. Müller, H. Köser, Water Sci Technol. 56, 145 (2007)

13. T. Saeed, G. Sun, Bioresour. Technol. 102, 1205 (2011)

14. O.R. Stein, B.W. Towler, P.B. Hook, J.A. Biederman, Water Sci Technol. 56, 93 (2007)

15. G. Sun, T. Saeed, Process Biochem. 44, 717 (2009)

16. J. Vymazal, H. Brix, P.F. Cooper, R. Haberl, R. Perfler, J. Laber, Removal mechanisms and types of constructed wetlands (Backhuys Publisher, 1998)

17. Y.Q. Zhao, G. Sun, S.J. Allen, Water Res. 38, 2907 (2004) 